\title{
Approaches to Cough Peak Flow Measurement With Duchenne Muscular Dystrophy
}

\author{
Kazuto Kikuchi RPT, Masahiro Satake RPT PhD, Yusuke Kimoto RPT PhD, \\ Satomi Iwasawa RPT MSc, Ryohei Suzuki RPT, Michio Kobayashi MD PhD, \\ Chizu Wada MD PhD, and Takanobu Shioya MD PhD
}

\begin{abstract}
BACKGROUND: Manually-assisted coughing and mechanical insufflation-exsufflation (MI-E) are commonly used in patients with Duchenne muscular dystrophy (DMD). Few studies have compared cough peak flow (CPF) with manually-assisted coughing to other methods, such as MI-E + manually-assisted coughing. In addition, few studies have reported the reliability of the measured CPF values. This study aimed to compare CPF with different cough-assistance methods and to examine the reliability of CPF data. METHODS: The study included 12 subjects with DMD (mean age, $34 \pm 8$ y). CPF, CPF + manually-assisted coughing (assisted CPF), maximum insufflation capacity (MIC) + CPF (MIC-CPF), MIC + manually-assisted coughing (MIC+assisted CPF), MI-E (MIE-CPF), and MI-E + assisted CPF were measured. A spirometer was used to compare CPF measurements obtained with each of the cough-assist techniques. The reliability of the measured CPF values was analyzed using Bland-Altman analysis. RESULTS: CPF was $59 \pm 34$ $\mathrm{L} / \mathrm{min}$, assisted CPF was $113 \pm 32 \mathrm{~L} / \mathrm{min}$, MIC-CPF was $170 \pm 30 \mathrm{~L} / \mathrm{min}, \mathrm{MIC}+$ assisted CPF was $224 \pm 62 \mathrm{~L} / \mathrm{min}$, MI-E-CPF was $199 \pm 40 \mathrm{~L} / \mathrm{min}$, and MI-E + assisted CPF was $240 \pm 38 \mathrm{~L} / \mathrm{min}$. A fixed and proportional bias was found in the CPF measurements made with the peak flow meter and the spirometer. The average $95 \% \mathrm{CI}$ in the difference between peak flow meter, MI-E, and CPF obtained using the spirometer were -7.45 to -1.95 and -1.45 to 4.95 , respectively. Test for correlation was $r=0.54(P<.001)$ for $\mathrm{CPF}$ (peak flow meter) and CPF (spirometer) and $\mathrm{r}=0.17$ $(P=.17)$ in CPF (MI-E) and CPF (spirometer), respectively. CONCLUSION: MI-E + assisted CPF was the highest. The CPF measured with the peak flow meter suggested underestimation. Key words: manually-assisted coughing; mechanical insufflation-exsufflation; cough peak flow; Duchenne muscular dystrophy. [Respir Care 2018;63(12):1514-1519. (0) 2018 Daedalus Enterprises]
\end{abstract}

\section{Introduction}

Cough peak flow $(\mathrm{CPF})$ is considered an index of expectoration of airway secretions in subjects with Duchenne muscular dystrophy (DMD). ${ }^{1,2}$ Manual or mechanical cough assistance is an approach to increase CPF. ${ }^{2}$ Manually-assisted

\footnotetext{
Mr Kikuchi is affiliated with the Department of Rehabilitation, Akita National Hospital, Yurihonjo City, Japan. Drs Satake, Kimoto, and Shioya, and Mr Suzuki and Mr Iwasawa are affiliated with the Department of Physical Therapy, Akita University, Graduate School of Health Sciences, Yurihonjo City, Japan. Drs Kobayashi and Wada are affiliated with the Department of Neurology, Akita National Hospital, Yurihonjo City, Japan.
}

The authors have disclosed no conflicts of interest. coughing (assisted $\mathrm{CPF}$ ) provides assistance with regard to inspiration and exhalation. ${ }^{3,4,5}$ There is a procedure to obtain maximum insufflation capacity (MIC), which is the volume of air that can be held in the lungs with the glottis closed, during inspiration assistance. ${ }^{6} \mathrm{CPF}$ with MIC support (MIC-CPF) was measured with voluntary coughing after breath stacking of 3 or 4 insufflations with a manual resuscitation bag-valve-mask. To measure the MIC+assisted $\mathrm{CPF}$, the subjects were deeply insufflated and then asked

Correspondence: Kazuto Kikuchi RPT, Department of Rehabilitation, Akita National Hospital, 84-40 Idonosawa, Iwaki Uchimichikawa, Yurihonjo City, Akita, Japan. E-mail: riha1@akitahp.jp.

DOI: $10.4187 /$ respcare.06124 
to forcefully cough, with the abdominal thrust timed to glottic opening. We used thoraco-abdominal compression during coughing as the exhalation assistance method. ${ }^{7}$

Assisted CPF provides support by pushing the upper abdomen or chest wall in synchrony with the subject's own coughing effort. Mechanical insufflation-exsufflation (MI-E) involves insufflation of the lungs with positive pressure, followed by exsufflation with active negative pressure that creates a peak and sustained flow high enough to provide adequate shear and velocity to loosen and move secretions toward the mouth for suctioning or expectoration. ${ }^{8}$ Mechanically-assisted coughing (MI-E-CPF) is an airway clearance method in which the thorax or abdomen is compressed in synchronization with MI-E. - $^{-10}$

In preliminary research on the augmentation of $\mathrm{CPF}, 9,10$ MI-E-CPF showed the highest value among the measured modalities: $\mathrm{CPF}$, maximum insufflation capacity $+\mathrm{CPF}$ (MIC-CPF), maximum insufflation capacity + manuallyassisted coughing (MIC+assisted CPF), and MI-E-CPF. In addition, in systematic reviews, MI-E produced the greatest CPF increase among all of the assessed procedures. ${ }^{11-13}$ Mechanically-assisted cough is not only effective, but research has shown that CPF actually increased. ${ }^{8-10}$ However, Kim et al ${ }^{14}$ reported that CPF increased more with mechanically-assisted coughing compared to MI-E. On the other hand, Lacombe et al ${ }^{15}$ reported that $\mathrm{MIC}+$ assisted $\mathrm{CPF}$ yielded significantly higher values than CPF associated with MI-E or mechanically-assisted coughing. A previous study showed that set pressures for MI-E vary (30$40 \mathrm{~cm} \mathrm{H}_{2} \mathrm{O}$ ), and this range may be too low for optimal effectiveness. ${ }^{15}$ Effectiveness is influenced by the set pressure of MI-E, and it is unknown whether MIC+ assisted CPF or MI-E-CPF produces the higher CPF.

Bach $^{16}$ reported that a set pressure of MI-E of $54 \mathrm{~cm}$ $\mathrm{H}_{2} \mathrm{O}$ is most effective. A peak flow meter is widely used for $\mathrm{CPF}$ evaluation because it is appropriate for continuous clinical assessment. ${ }^{2}$ Although a peak flow meter is accurate when the $\mathrm{CPF}$ is $\geq 270 \mathrm{~L} / \mathrm{min}$, there is a possibility of overestimation when the value is $<270 \mathrm{~L} / \mathrm{min}^{17}{ }^{17}$ In addition, it has been reported that $\mathrm{CPF}$ measured using a peak flow meter is lower than that measured using a differential pressure-type flow meter (pneumotachograph). ${ }^{17}$ Thus, instrumental differences in measurement may influence the error in measurement. Preliminary research comparing various cough-assist techniques used CPF values obtained from a pneumotachograph. It is necessary to examine the reliability of CPF measured using a peak flow meter and MI-E to determine the significance of measurement with the same instrument and to perform comparisons. To compare measured values obtained from the same equipment, it is necessary to investigate the reliability of CPF measured using a peak flow meter and MI-E.

\section{QUICK LOOK}

\section{Current knowledge}

Measurement of cough peak flow (CPF) is possible using a peak flow meter and a mechanical insufflationexsufflation (MI-E) display. The set pressure of MI-E varies according to the patient's condition.

\section{What this paper contributes to our knowledge}

There was no statistically significant difference in CPF due to differences in MI-E $\left( \pm 40 \mathrm{~cm} \mathrm{H}_{2} \mathrm{O}\right.$ ), maximum insufflation capacity + manually-assisted coughing, and MI-E + manually-assisted coughing. Using spirometry results as a standard, the CPF displayed on the MI-E device had high reliability. There was a negative fixed bias in the CPF of the peak flow meter.

The purpose of this study was to compare and assess the reliability of cough-assisted CPF to determine the most effective cough-assistance approach for subjects with DMD.

\section{Methods}

This cross-sectional study included 12 subjects with DMD admitted to Akita National Hospital. The mean age was $34 \pm 8 \mathrm{y}$, and the period of hospital stay was $13 \pm 8 \mathrm{y}$. Six subjects received noninvasive ventilation for $1 \mathrm{~d}$. Six subjects who carried out activities of daily living all required assistance (Table 1). The inclusion criteria were age $>12 \mathrm{y}, \mathrm{CPF}$ $<160 \mathrm{~L} / \mathrm{min}$, and the use of MI-E. The exclusion criteria were history of previous pneumothorax and no requirement of MI-E in patients with CPF $>160 \mathrm{~L} / \mathrm{min}$. The criteria for cancellation of treatment were rejection by the patient, fatigue, hyperventilation, worsening of oxygenation, sense of incongruity, intragastric air inhalation, and barotrauma. We explained the purpose and methods of the research to all subjects, the expected effects, the benefits of research cooperation, and the ability to appeal after reporting any adverse effects. We informed them that no identifying information would be used so as to protect their privacy. Subjects who provided informed consent were included. This study was approved by the ethics committee of Akita National Hospital (IRB No. 28/5).

For the measurement of CPF, assisted CPF, MIC-CPF, and $\mathrm{MIC}+$ assisted CPF, an automatic spirometer for electronic diagnosis (Auto Spiro AS 507, Minato, Tokyo, Japan) and a peak flow meter (Philips Respironics, Bend, Oregon) were connected (Fig. 1). The same examiner performed 2 random measurements on the same day. The transducer of the automatic spirometer was connected to the mouthpiece of the peak flow meter with tape. CPF was 
Table 1. Characteristics of Subjects With DMD

\begin{tabular}{lr}
\hline \hline Age, $\mathrm{y}$ & $34 \pm 8.2$ \\
Height, $\mathrm{cm}$ & $158.5 \pm 9.5$ \\
Weight, $\mathrm{kg}$ & $36.6 \pm 9.7$ \\
Body mass index, $\mathrm{kg} / \mathrm{m}^{2}$ & $14.6 \pm 3.3$ \\
Length of hospital stay, y & $12.8 \pm 8.8$ \\
Diet & \\
$\quad$ Solid (ordinary diet), $n$ & 5 \\
$\quad$ Soft or Brenda (dysphagic diet), $n$ & 7 \\
Vital capacity, mL & $385.8 \pm 239.1$ \\
Maximum insufflation capacity, $\mathrm{mL}$ & $1570 \pm 523.8$ \\
Cough peak flow, L/min & $44 \pm 43$ \\
Ventilation duration, $\mathrm{h}$ & $15.1 \pm 8.5$ \\
Scoliosis, $n$ & 6 \\
\hline Values are presented as mean \pm SD unless otherwise noted. $N=12$ subjects. \\
\hline
\end{tabular}

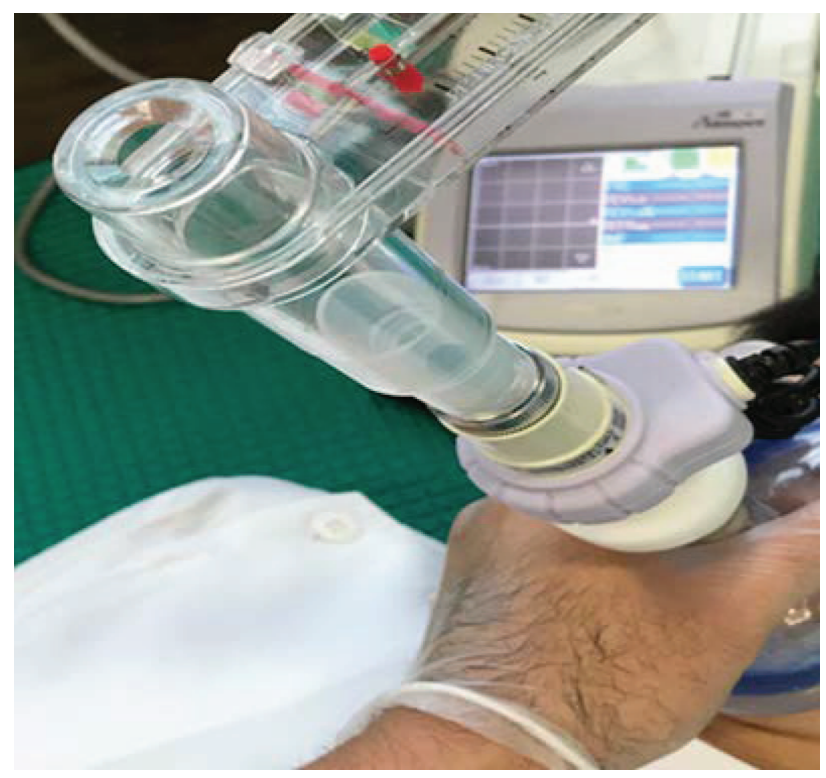

Fig. 1. Connection of the spirometer (Minato) and peak flow meter (Philips Respironics).

obtained using the peak expiratory flow output from the spirometer and the value from the peak flow meter. For the measurement of MI-E-CPF and MI-E+ assisted CPF, an automatic spirometer and MI-E (Cough Assist E 70, Philips Respironics) were connected (Fig. 2).

Regarding the connection method, a flexible tube was connected to the MI-E device, the transducer of the automatic spirometer was connected, and a mask was connected. The peak expiratory flow output from the automatic spirometer was recorded as $\mathrm{CPF}(\mathrm{s})$, and the $\mathrm{CPF}$ on the MI-E display was recorded as $\mathrm{CPF}(\mathrm{m})$. Without using an airway pressure meter for MIC measurement in MIC$\mathrm{CPF}$ and MIC+ assisted CPF, we pressurized a bag-valvemask until subjects could not inhale further. The examin-

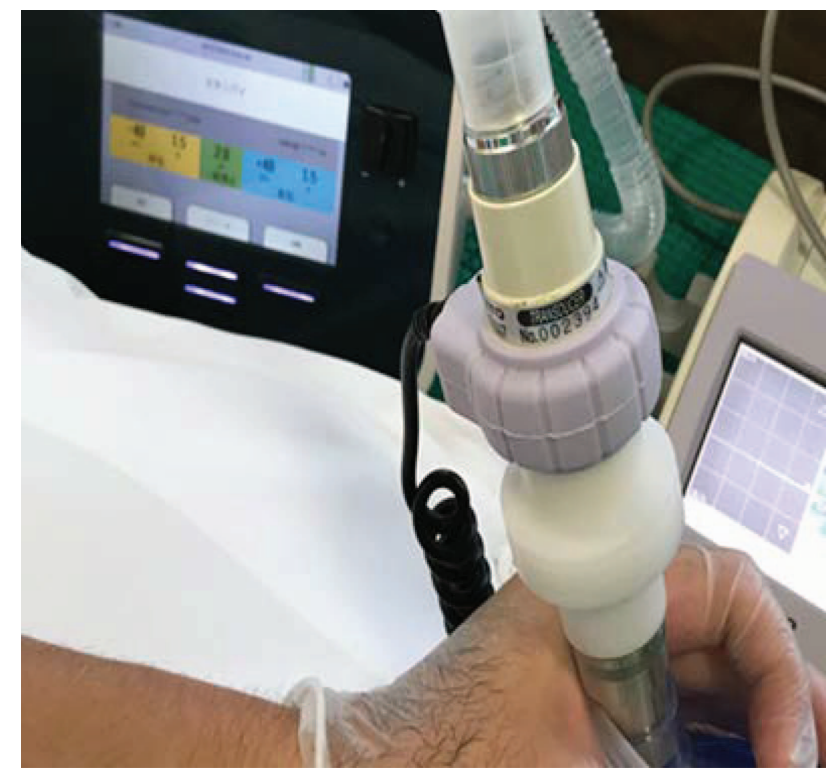

Fig. 2. Connection of the spirometer (Minato) and mechanical insufflation-exsufflation device (Philips Respironics).

er's pressurization method was subjectively judged according to the resistance of the bag-valve-mask, and there were no criteria. In addition, the MI-E setting used was $\pm 40 \mathrm{~cm} \mathrm{H}_{2} \mathrm{O}(1.5 \mathrm{~s})$, with a rest time of $2 \mathrm{~s}$. Whereas a study by Bach and Mehta ${ }^{18}$ identified $54.1 \mathrm{~cm} \mathrm{H}_{2} \mathrm{O}$ as the most effective pressure, we used a setting pressure that is most frequently used in the clinical setting..$^{8,19,20}$

Measurements were performed in the supine position because the electric wheelchairs used by subjects do not have a reclining and tilt function, and subjects were unable to maintain a seated position in the hospital bed.

\section{Statistical Analysis}

To compare the CPF of each of the cough-assistance approaches, we mainly used CPF measured with a spirometer, indicated as $\mathrm{CPF}(\mathrm{s})$. For statistical analysis, one-way analysis of variance and a multiple comparison test (Tukey method) were used. To assess the relationship between $\mathrm{CPF}(\mathrm{s})$ and $\mathrm{CPF}(\mathrm{p})$ and between $\mathrm{CPF}(\mathrm{s})$ and $\mathrm{CPF}(\mathrm{m})$, Spearman's rank correlation coefficient was used for relative reliability. Bland-Altman analysis was used for absolute reliability. ${ }^{21}$ If a systematic error was noted, the 95\% limit of agreement ranges were calculated; however, if there was no systematic error, the $95 \%$ minimal detectable change was calculated. For all statistical analyses, Statcel 3 (OMS Publishing, Tokyo, Japan) was used.

\section{Results}

The $\mathrm{CPF}(\mathrm{s})$ values obtained from the automatic spirometer were as follows: $\mathrm{CPF}, 59 \pm 35 \mathrm{~L} / \mathrm{min}$; assisted $\mathrm{CPF}$, 
Table 2. Comparison of Unassisted/Manual and Mechanically Assisted Cough Peak Flow (Spirometer)

\begin{tabular}{|c|c|c|c|c|c|}
\hline $\mathrm{CPF}$ & Assisted CPF & MIC-CPF & MIC + assisted CPF & MI-E-CPF & MI-E + assisted CPF \\
\hline $59 \pm 34.2$ & $112.9 \pm 31.8^{*}$ & $170.3 \pm 30 \dagger+$ & $224.3 \pm 61.8 \dagger \S \|$ & $198.8 \pm 40.2 \dagger \S$ & $240 \pm 38.4 \uparrow \S \llbracket$ \\
\hline $\begin{array}{l}\text { Values are pres } \\
* \text { Compared wi } \\
\dagger \text { Compared wi } \\
\text { ‡Compared wi } \\
\text { \& Compared wi } \\
\| \text { Compared wi } \\
\text { II Compared wi } \\
\text { CPF = unassis } \\
\text { assisted CPF = } \\
\text { MIC-CPF = m } \\
\text { MIC + assistec } \\
\text { MI-E-CPF = I }\end{array}$ & $\begin{array}{l}\text { ean } \pm \mathrm{SD} . \\
<.001) . \\
<.001) . \\
\mathrm{CPF}(P<.001) . \\
\mathrm{CPF}(P<.001) . \\
\mathrm{F}(P<.001) . \\
\mathrm{F}(P<.001) \\
\text { peak flow } \\
\text { anually-assisted cough } \\
\text { sufflation capacity }+ \\
\text { IC + manually-assist } \\
\mathrm{F}\end{array}$ & $+\mathrm{CPF}$ & & & \\
\hline
\end{tabular}

$113 \pm 32 \mathrm{~L} / \mathrm{min} ; \mathrm{MIC}-\mathrm{CPF}, 170 \pm 30 \mathrm{~L} / \mathrm{min} ; \mathrm{MIC}+$ assisted CPF, $224 \pm 62 \mathrm{~L} / \mathrm{min}$; MI-E-CPF, $199 \pm 40 \mathrm{~L} / \mathrm{min}$; and MI-E+assisted CPF, $240 \pm 38 \mathrm{~L} / \mathrm{min}$. Compared with unassisted $\mathrm{CPF}$, the $\mathrm{CPF}$ value was higher with all the cough-assistance methods. In addition, CPF increased when inspiration and exhalation assistance were provided rather than when only exhalation assistance was provided. There was no statistically significant difference among MI-E-CPF, MIC+assisted CPF, and MI$\mathrm{E}+$ assisted $\mathrm{CPF}$, which were considered high according to the guidelines. ${ }^{12,13}$ However, the highest value was for MI-E+assisted CPF (Table 2).

The sample size of $\mathrm{CPF}(\mathrm{p})$ and $\mathrm{CPF}(\mathrm{s})$ was 96 , and the sample size of $\mathrm{CPF}(\mathrm{m})$ and $\mathrm{CPF}(\mathrm{s})$ was 48 . The correlation findings of $\mathrm{CPF}(\mathrm{p})$ and $\mathrm{CPF}(\mathrm{s})$ were as follows: $\mathrm{CPF}$ (rs $=0.93, P<.001, n=24)$, assisted CPF (rs $=0.97$, $P<.001, n=24)$, MIC-CPF $(\mathrm{rs}=0.81, P<.001$, $n=24$ ), and MIC + assisted $\mathrm{CPF}$ ( $\mathrm{rs}=0.96, P<.001$, $n=24)$. The correlation findings of $\mathrm{CPF}(\mathrm{m})$ and $\mathrm{CPF}(\mathrm{s})$ were as follows: MI-E-CPF ( $\mathrm{rs}=0.94, P<.001, n=24)$ and MI-E + assisted CPF ( $\mathrm{rs}=0.98, \mathrm{P}<.001, n=24$ ). Regarding the Bland-Altman analysis, agreement between the measurement of CPF obtained with the spirometer and peak flow meter was assessed using data from $\mathrm{CPF}$, assisted CPF, MIC-CPF, and MIC + assisted CPF $(n=96)$. Subsequently, the agreement between the measurements of CPF obtained with the spirometer versus measurements obtained with MI-E was evaluated, using MI-E-CPF and MI-E+assisted CPF data $(n=48)$. In the Bland-Altman analysis, a fixed and proportional bias was found in $\mathrm{CPF}(\mathrm{p})$ and $\mathrm{CPF}(\mathrm{s})$ at sample a size of $n=96$. The average $95 \%$ $\mathrm{CI}$ in the difference between $\mathrm{CPF}(\mathrm{p}), \mathrm{CPF}(\mathrm{m})$, and $\mathrm{CPF}(\mathrm{s})$ were -7.45 to -1.95 and -1.45 to 4.95 , respectively. Bland-Altman analysis of CPF measurements indicated that the $\mathrm{CPF}(\mathrm{p})$ measurements were markedly lower than the $\mathrm{CPF}(\mathrm{s})$ measurements [bias (mean $95 \%$ limit of agreement), $-4.7 \mathrm{~L} / \mathrm{min}$ ( -30.7 to $21.3 \mathrm{~L} / \mathrm{min})$ ] (Fig. 3). Test for no correlation was $\mathrm{r}=0.54(P<.001)$ [bias (mean $95 \%$ limit of agreement $)-4.7 \mathrm{~L} / \mathrm{min}(-128.7$ to $76.6 \%)]$.

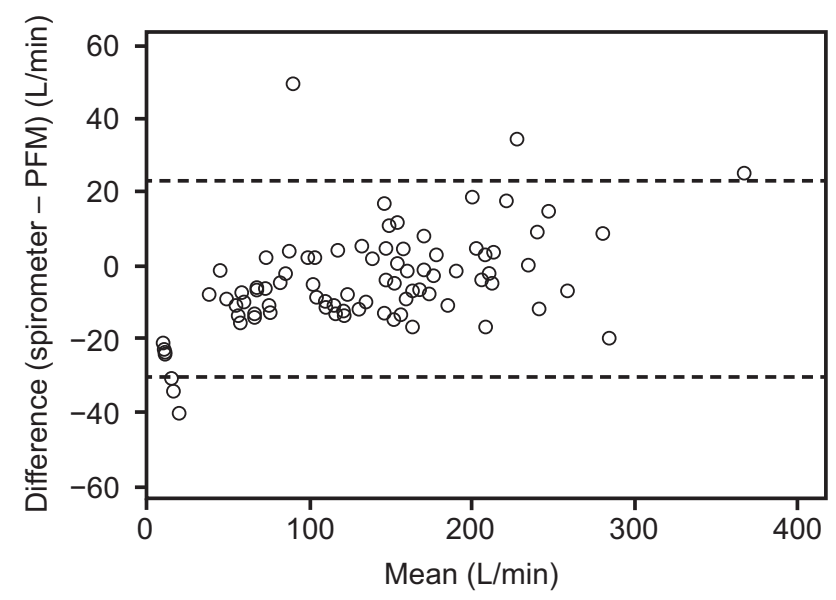

Fig. 3. Bland-Altman plot representing the agreement between cough peak flow measurements obtained with a spirometer and with a peak flow meter. The difference between the 2 measurements is plotted against the mean of the 2 measurements. The solid and dashed lines indicate the difference between measurements (bias) and the upper and lower 95\% limits of agreement (bias $\pm 1.96 \mathrm{SD}$ ).

There was no proportional or fixed bias in $\mathrm{CPF}(\mathrm{m})$ and $\mathrm{CPF}(\mathrm{s})$ at a sample size of $n=48$ (Fig. 4). The 95\% minimal detectable change for $\mathrm{CPF}(\mathrm{m})$ and $\mathrm{CPF}(\mathrm{s})$ was $21.8 \mathrm{~L} / \mathrm{min}$. Test for no correlation was $\mathrm{r}=0.17(P=.17)$.

\section{Discussion}

In this study, the CPF of unassisted and manual/mechanically-assisted coughing was compared using the same equipment. There was no statistically significant difference in MIC+ assisted CPF and MI-E+ assisted CPF when compared with $\mathrm{CPF}(\mathrm{s}) \mathrm{MI}-\mathrm{E}$ obtained using the automatic spirometer, which was connected to the peak flow meter and MI-E. Using the automatic spirometer, we examined the reliability of the peak flow meter and MI-E. In BlandAltman analysis, negative fixed bias and proportional bias 


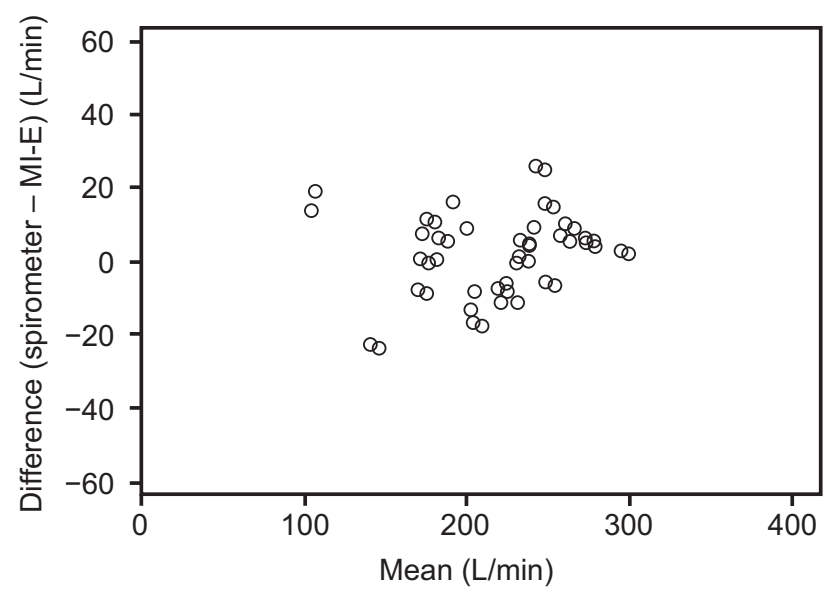

Fig. 4. Bland-Altman plot representing the agreement between cough peak flow (CPF) measurements obtained with a spirometer and with a mechanical insufflation-exsufflation (MI-E) device. The difference between the 2 measurements is plotted against the mean of the 2 measurements. There was no proportional or fixed bias of CPF determined with MI-E and CPF determined with automatic spirometry.

were recognized for peak flow meter and CPF from spirometer. The $95 \%$ minimal detectable change for $\mathrm{CPF}(\mathrm{m})$ and $\mathrm{CPF}(\mathrm{s})$ was $21.8 \mathrm{~L} / \mathrm{min}$, and the limit of agreement of $\mathrm{CPF}(\mathrm{p})$ and $\mathrm{CPF}(\mathrm{s})$ was -30.7 to $21.3 \mathrm{~L} / \mathrm{min}$.

Our hypothesis was that MI-E-CPF has the highest value. However, we found no significant difference among $\mathrm{MIC}+$ assisted CPF, MI-E+ assisted CPF, and MI-E-CPF. The pressure of MI-E in this study was $\pm 40 \mathrm{~cm} \mathrm{H}_{2} \mathrm{O}$. On the other hand, there was no upper limit on the pressure of the bag-valve-mask. The bag-valve-mask pressure might have been higher than the MI-E pressure, and inspiration might have been higher than the MI-E value. In addition, the pressure in the MIC procedure might have been higher than that in the MI-E procedure. Therefore, we believe that the amount of inspiration was high.

In a previous study, it was shown that CPF increased as MIC increased. ${ }^{22}$ In other words, the bag-valve-mask pressure was higher than the MI-E pressure, which is considered to be different from MI-E-CPF due to the increase in the volume of air intake. In MIC+assisted CPF, high peak flow is achieved by creating high intrathoracic pressure, whereas MI-E shifts instantly from positive to negative pressure to simulate the pressure differential achieved with the normal cough mechanism. Patients must make adjustments during the shift from inspiration to expiration during MI-E, therefore pharyngeal function should be maintained. In a study of laryngeal responses in MI-E among healthy volunteers, it was noted that some people reported laryngeal obstruction at negative pressure. ${ }^{23}$ This may be because the timing of MI-E and coughing do not match. Regarding the comparison of the CPF values of a pneumotachograph and peak flow meter, the peak flow meter has been shown to have a higher or lower value, and a consensus has not yet been reached. ${ }^{18,24}$

The operating principle of the peak flow meter is the measurement of CPF at the position indicated when the piston held by the spring moves according to the expiratory flow rate. In the automatic spirometer, the measurement is derived using the volume calculated from the flow measured using a hot wire-type flow meter. It is thought that the measurement value is influenced by differences in the sensitivities of the measurement approaches. In previous studies, a pneumotachograph was considered more sensitive, and a previous study reported that it is accurate for subjects with cough deterioration. ${ }^{24}$ The findings of this study support the latter results, with the CPF measured with the automatic spirometer being the most accurate.

The present study has some limitations. First, the set pressure of MI-E was $40 \mathrm{~cm} \mathrm{H}_{2} \mathrm{O}$, which was used in preliminary research and is a common setting. However, the optimal pressure of MI-E should be determined according to the condition of the patient. Additional research on the optimal inspiratory pressure settings for MI-E would be useful. Second, we aimed to compare MI-E and MIC at the same pressure, but there might have been an increase in dead space and air leakage with the connections between the peak flow meter and spirometer, which could lead to some degree of error in our measurements. This error in the peak flow meter measurement was influenced by the method of air entrainment used by the bag-valvemask. There could also be variations in our results secondary to differences in the performance of the bag-valvemask procedure.

\section{Conclusion}

In this study, among subjects with DMD, there were no statistically significant differences among MI-E-CPF, $\mathrm{MIC}+$ assisted CPF, and MI-E+assisted CPF. Using spirometry as the standard, the CPF displayed on the MI-E device has a high reliability. However, there was a negative fixed bias in the CPF of the peak flow meter. Therefore, the peak flow meter may underestimate the true value of CPF.

\section{REFERENCES}

1. Suarez AA, Pessolano FA, Monteiro SG, Ferreyra G, Capria ME, Mesa L, et al. Peak flow and peak cough flow in the evaluation of expiratory muscle weakness and bulbar impairment in patients with neuromuscular disease. Am J Phys Med Rehabil 2002;81(7):506511.

2. Bach JR, Saporito LR. Criteria for extubation and tracheostomy tube removal for patients with ventilatory failure. A different approach to weaning. Chest 1996;110(6):1566-1571.

3. Sivasothy P, Brown L, Smith IE, Shneerson JM. Effect of manually assisted cough and mechanical insufflation on cough flow of normal subjects, patients with chronic obstructive pulmonary disease 


\section{CPF Measurement in Duchenne Muscular Dystrophy}

(COPD), and patients with respiratory muscle weakness. Thorax 2001;56(6):438-444.

4. Bach JR, Ishikawa Y, Kim H. Prevention of pulmonary morbidity for patients with Duchenne muscular dystrophy. Chest 1997;112(4): 1024-1028.

5. Dohna-Schwake C, Ragette R, Teschler H, Voit T, Mellies U. Predictors of severe chest infections in in pediatric neuromuscular disorders. Neuromuscul Disord 2006;16(5):325-328.

6. Kang SW, Bach JR. Maximum insufflation capacity. CHEST 2000; 118(1):61-65.

7. Ishikawa Y, Bach JR, Komaroff E, Miura T, Jackson-Parekh R. Cough augmentation in Duchenne muscular dystrophy. Am J Phys Med Rehabil 2008;87(9):726-730.

8. Douglas N. Homnick. mechanical insufflation-exsufflation for airway mucus clearance. Respir Care 2007;52(10):1296-1307.

9. Chatwin M, Ross E, Hart N, Nickol AH, Polkey MI, Simonds AK. Cough augmentation with mechanical insufflation/exsufflation in patients with neuromuscular weakness. Eur Respir J 2003;21(3):502-508.

10. Bach JR. Mechanical insufflation-exsufflation: comparison of peak expiratory flows with manually assisted and unassisted coughing techniques. Chest 1993;104(5):1553-1562.

11. Anderson JL, Hasney KM, Beaumont NE. Systematic review of techniques to enhance peak cough flow and maintain vital capacity in neuromuscular disease: the case for mechanical insufflation-exsufflation. Phys Ther Rev 2005;10(1):25-33.

12. McCool FD, Rosen MJ. Nonpharmacologic airway clearance therapies: ACCP evidence-based clinical practice guidelines. Chest 2006; 129 (1 Suppl):250S-259S.

13. Bott J, Blumenthal S, Buxton M, Ellum S, Falconor C, Garrod R, et al. Guidelines for the physiotherapy management of the adult, medical, spontaneously breathing patient. Thorax 2009;64(Suppl I):i1-i51.

14. Kim SM, Choi WA, Won YH, Kang SW. A comparison of cough assistance techniques in patients with respiratory muscle weakness. Yonsei Med J 2016;57(6):1488-1493.
15. Lacombe M, Del Amo Castrillo L, Boré A, Chapeau D, Horvat E, Vaugier I, et al. Comparison of three cough-augmentation techniques in neuromuscular patients: mechanical insufflation combined with manually assisted cough, insufflation-exsufflation alone and insufflation-exsufflation combined with manually assisted cough. Respiration 2014;88(3):215-222.

16. Bach JR. Noninvasive respiratory management of patients with neuromuscular disease. Ann Rehabil Med 2017;41(4):519-538.

17. Sancho J, Servera E, Diaz J, Marin J. Comparison of peak cough flows measured by pneumotachograph and a portable peak flow meter. Am J Phys Med Rehabil 2004;83(8):608-612.

18. Bach JR, Mehta A. Respiratory muscle aids to avert respiratory failure and tracheostomy: a new patient management paradigm. Journal of Neurorestoratology 2014;2:25-35.

19. Boitano LJ. Management of airway clearance in neuromuscular disease. Respir Care 2006;51(8):913-922.

20. Gonçalves MR, Honrado T, Winck JC, Paiva JA. Effects of mechanical insufflation-exsufflation in preventing respiratory failure after extubation: a randomized controlled trial. Crit Care 2012;16(2):R48.

21. Bland JM, Altman DG. Statistical methods for assessing agreement between two methods of clinical measurement. Lancet 1986;1(8476): 307-310.

22. Kang SW, Bach JR. Maximum insufflation capacity: vital capacity and cough flows in neuromuscular disease. Am J Phys Med Rehabil 2000;79(3):222-227.

23. Andersen T, Sandnes A, Hilland M, Halvorsen T, Fondenes O, Heimdal JH, et al. Laryngeal response patterns to mechanical insufflationexsufflation in healthy subjects. Am J Phys Med Rehabil 2013; 92(10):920-929.

24. Rodrigues PR, Brito PU, Fernandes L, Rodrigues C, Reis A, Moita J. Peak cough flow measurement with a pneumotacograph and a portable peak flow meter in patients with neuromuscular diseases. Rev Port Pneumol 2017;23(1):39-42. 